\title{
EDUCAÇÃO FÍSICA: DESPERTANDO HABILIDADES E COMPETÊNCIAS NAS CRIANÇAS AUTISTAS
}

\author{
Marlucia de Souza Barbosa1
}

\section{RESUMO}

Esse artigo aborda a importância das aulas adaptadas de Educação Física nas escolas públicas com o intuito de atender às reais necessidades das crianças autistas, visando o desenvolvimento pleno de suas potencialidades no Ensino Fundamental I e II. Será mencionado o depoimento de uma mãe acerca do avanço das potencialidades de seu filho, em especial nas aulas desse componente. Apresentar-se-ão relatos da experiência de um Professor e Terapeuta que desenvolve um trabalho de Ginástica Artística com crianças autistas.

Palavras-chave: Autismo; TGD; Educação Física; Integração Sensorial.

\section{ABSTRACT}

This article addresses the importance of adapted physical education classes in public schools in order to meet the real needs of autistic children, aiming at the full development of their potential in Elementary School I and II. Reports will be presented of the experience of a Teacher and Therapist who develops an artistic gymnastics work with autistic children.

Keywords: Autism; TGD; Physical Education; Sensory Integration.

\section{RESUMEN}

Este artículo aborda la importancia de las clases de educación física adaptadas en las escuelas públicas con el fin de satisfacer las necesidades reales de los niños autistas, con el objetivo de lograr el pleno desarrollo de su potencial en las escuelas primarias I y II. Se presentarán informes de la experiencia de un Profesor y Terapeuta que desarrolla un trabajo de gimnasia artística con niños autistas.

Palabras clave: Autismo; TGD; Educación Física; Integración Sensorial.

${ }^{1}$ Pedagoga, especialista em Psicopedagogia Institucional e Clínica. E-mail: marlucia.barbosa@sme.prefeitura.sp.gov.br 


\section{INTRODUÇÃO}

Ser mãe de uma criança com Autismo nos torna uma pessoa melhor, criteriosa, disposta a buscar diversas formas de aprendizagem e que está sempre à procura de alternativas para desenvolver as habilidades e competências dessa criança nas diversas áreas do conhecimento. Encarar a realidade é o primeiro passo, pois é preciso ser forte, resiliente para dar início à longa jornada, afinal, as pessoas não estão preparadas para lidar com as diferenças. O preconceito venda os olhos de alguns profissionais que ainda não têm vontade ou talvez coragem de ousar e acreditar na capacidade que os autistas possuem de aprender.

Aos dez anos de idade, (O.A.) é aluno da escola pública no município de São Bernardo do Campo - SP e sua evolução nos aspectos: social, motor/físico e linguístico vêm aumentando gradativamente. A família tem percebido atentamente que sua participação nas atividades desenvolvidas nas aulas de Educação Física ganhou destaque, principalmente, durante as Olimpíadas de 2016.

Pretende-se apresentar por meio de relatos, a importância que as atividades físicas desenvolvidas dentro e fora da escola têm na vida de uma criança com autismo, já que o esporte é uma excelente ferramenta para integrá-las, sobretudo, incluí-las.

Será apresentada, neste artigo, uma entrevista com uma professora de Educação Física e relatos de um Terapeuta que, pelo fato de trabalharem com crianças autistas, destacam os aspectos positivos que a prática de esportes proporciona a essas crianças.

\section{O TRANSTORNO DO ESPECTRO AUTISTA (TEA) E SUAS FACETAS}

O termo Autismo foi utilizado pela primeira vez em 1911, por Eugen Bleuler (1857-1939) psiquiatra suíço, criador do termo esquizofrenia, iniciador da nova psiquiatria do século $\mathrm{XX}$ e um reformador do tratamento de loucura. Autismo refere-se à perda do contato com a realidade e consequente dificuldade ou impossibilidade de comunicação. 
Em 1943, o médico austríaco radicado nos Estados Unidos da América -

Leo Kanner - observou onze crianças que passaram por sua consulta e escreveu o artigo Os transtornos autistas do contato de comunicação (KANNER, 1943).

Vejamos como Kanner descreve o autismo:

\begin{abstract}
Nas relações sociais e afetivas: Desde o início há uma extrema solidão autista, algo que, na medida do possível, desconsidera, ignora ou impede a entrada de tudo o que chega à criança de fora. O contato físico direto e os movimentos ou ruídos que ameaçam romper a solidão são tratados como se não estivessem ali.

Na comunicação e a linguagem: Há ausência da linguagem (mutismo) em algumas crianças, seu uso estranho nas que a possuem, a presença de ecolalia.

$\mathrm{Na}$ relação com as mudanças no ambiente e na rotina: A conduta da criança "é governada por um desejo ansiosamente obsessivo por manter a igualdade, que ninguém, a não ser ela mesma, pode romper em raras ocasiões.

Memória: Capacidade surpreendente de alguns em memorizar grande quantidade de material sem sentido ou efeito prático.

Hipersensibilidade a estímulos: Muitas crianças reagiram intensamente a certos ruídos e a alguns objetos. Também manifestavam problemas com a alimentação (KANNER, 1943).
\end{abstract}

Poucos meses depois de Kanner, o médico vienense Hans Asperger descreveu os casos de várias crianças vistas e atendidas na Clínica Pediátrica Universitária de Viena. Asperger descobriu o autismo de modo independente, pois não conhecia o trabalho de Kanner.

As descrições do autismo feitas por Asperger foram publicadas em alemão, no pós-guerra, e não foram traduzidas para outra língua, o que provavelmente contribuiu para prolongar o período de desconhecimento a respeito de seus estudos, até a década de 80.

Hans Asperger descreveu o Autismo da seguinte forma:

Nas relações sociais: Identificava como traço fundamental a limitação de suas relações sociais, considerando que toda a personalidade da criança está determinada por esta limitação.

$\mathrm{Na}$ comunicação e linguagem: Apresentam anomalias prosódicas e pragmáticas. As anomalias prosódicas são alterações acústicas da fala-ritmo e entonação, constituindo uma fala estranha. As anomalias pragmáticas dizem respeito a uma comunicação restrita a significados implícitos ou a serem inferidos, possuem dificuldade de compreensão de palavras ou expressões.

Pensamento: Compulsividade e caráter obsessivo de seus pensamentos.

Comportamento e atitudes: Tendências a guiar-se de forma alheia às condições do meio (KANNER, 1943). 
Asperger se preocupava com o aspecto educacional das crianças, para Kanner (1943), isso não fazia parte de seus estudos. Esse era um grande diferencial entre eles.

O Transtorno do Espectro Autista (TEA) engloba diferentes síndromes marcadas por perturbações do desenvolvimento neurológico com três características fundamentais, que podem manifestar-se em conjunto ou isoladamente. São elas: dificuldade de comunicação por deficiência no domínio da linguagem e no uso da imaginação para lidar com jogos simbólicos, dificuldade de socialização e padrão de comportamento restritivo e repetitivo.

O diagnóstico é essencialmente clínico, já que se baseia nos sinais e sintomas e leva em conta os critérios estabelecidos por DSM-IV (Manual de Diagnóstico e Estatística da Sociedade Norte-Americana de Psiquiatria) e pelo CID10 (Classificação Internacional de Doenças da OMS) o comprometimento e o histórico do paciente.

Estudos iniciais consideravam o transtorno resultado de dinâmica familiar problemática e de condições de ordem psicológica alteradas, hipótese que se mostrou improcedente. A tendência atual é admitir a existência de múltiplas causas para o autismo, entre eles, fatores genéticos, biológicos e ambientais. No entanto, saber como o cérebro dessas pessoas ainda é um mistério para ciência.

Ainda não se conhece a cura definitiva para o transtorno do espectro do autismo. Da mesma forma não existe um padrão de tratamento que possa ser aplicado em todos os portadores do distúrbio. Cada paciente exige um tipo de acompanhamento específico e individualizado que exige a participação dos pais, dos familiares e de uma equipe profissional multidisciplinar visando à reabilitação global do paciente. O uso de medicamentos só é indicado quando surgem complicações e comorbidades.

A ausência da oferta de educação escolar, durante os primeiros anos de estudo do Autismo, leva as famílias a viver seus desafios e necessidades à parte das demais. As primeiras iniciativas de escolarização foram patrocinadas por familiares e pais de autistas. E não pelo estado ou por profissionais e estudiosos da educação.

Podemos dimensionar a importância do momento atual da educação brasileira para as crianças com Autismo e suas famílias. A empreitada nacional, empreendida por pais e gestores no sentido de constituir sistemas de ensino 


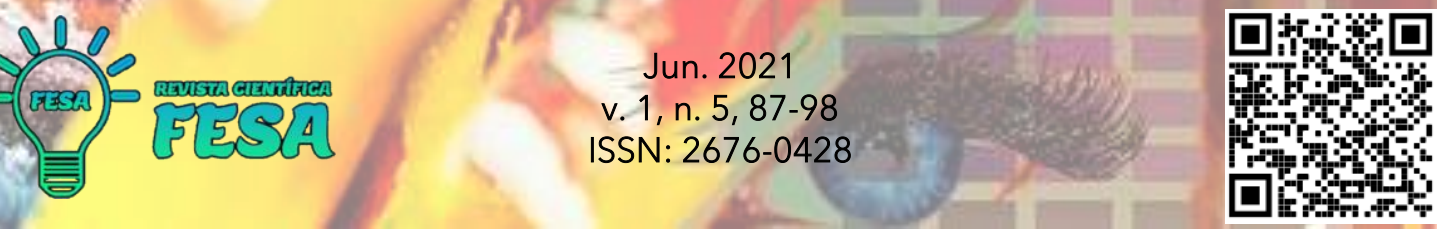

inclusivos, vem tirando as crianças com Autismo e suas famílias do isolamento social histórico.

Atualmente, é difícil encontrar quem se oponha publicamente ao convívio de crianças com algum tipo de deficiência com outras de sua idade, tanto para o desenvolvimento social e educacional como para diminuir o preconceito. Porém, no Brasil, a realidade da rede pública de ensino ainda é de salas superlotadas, baixos salários, má formação dos professores, projetos pedagógicos ultrapassados e estrutura precária, o que dificulta a aprendizagem de qualquer criança. Os defensores da inclusão acreditam que a entrada dos alunos com deficiência no ambiente educacional regular vai pressionar as escolas a se reestruturarem física e pedagogicamente, respeitando o ritmo de aprendizagem de cada aluno, tenha ele uma deficiência ou não."

Em algumas cidades do país, foram criados os Conselhos Municipais que dão voz à sociedade civil para reivindicar pelos seus direitos. Em São Bernardo do Campo, o Conselho Municipal da Pessoa com Deficiência tem realizado um belo e valioso trabalho, ouvindo as demandas, lutando pelos direitos já adquiridos e de forma atuante, propondo a construção de novos direitos.

As escolas municipais, atendendo aos pressupostos do artigo 24 da Convenção dos Direitos das Pessoas com Deficiência, tem garantido a Educação Inclusiva de qualidade subsidiada pela LBI 13.146 (Lei Brasileira de Inclusão), sancionada pela presidenta Dilma Rousseff em 6 de julho de 2015. Conforme a Lei 12.764/12, a pessoa autista é considerada para todos os fins, pessoa com deficiência (Art. 1ํㅡ - Lei 12.764/12). Portanto, todos os direitos assegurados pela LBI se aplicam também às pessoas autistas.

A pessoa com deficiência é aquela que possui impedimento de longo prazo de natureza física, mental, intelectual ou sensorial, o qual, em interação com uma ou mais barreiras, pode obstruir sua participação plena e efetiva na sociedade em igualdade de condições com as demais pessoas (Art. $2^{\circ}$ ).

\section{DEFINIÇÃO DE TRANSTORNOS GLOBAIS DO DESENVOLVIMENTO}

O conceito de Transtornos Globais do Desenvolvimento surgiu no final dos anos 60, traduzindo o Autismo como um transtorno do desenvolvimento. O Autismo é explicado e descrito como um conjunto de transtornos qualitativos de 


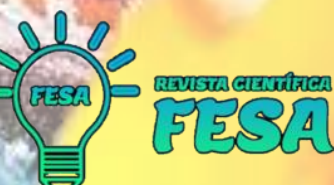

funções envolvidas no desenvolvimento humano, desta forma, ele não foi mais classificado como psicose infantil.

O Transtorno Global do Desenvolvimento não diz respeito apenas ao Autismo. Sob essa classificação, se descrevem diferentes transtornos que têm em comum as funções do desenvolvimento afetadas qualitativamente.

Os Transtornos Globais do Desenvolvimento (TGD) são distúrbios nas interações sociais recíprocas que costumam manifestar-se nos primeiros cinco anos de vida. Caracterizam-se pelos padrões de comunicação estereotipados e repetitivos, assim como pelo estreitamento nos interesses e nas atividades.

Os TGD englobam os diferentes transtornos do espectro autista, as psicoses infantis, a Síndrome de Asperger, a Síndrome de Kanner e a Síndrome de Rett.

Com relação à interação social, crianças com TGD apresentam dificuldades em iniciar e manter uma conversa. Algumas evitam o contato visual e demonstram aversão ao toque do outro, mantendo-se isoladas. Podem estabelecer contato por meio de comportamentos não-verbais e, ao brincar, preferem ater-se a objetos no lugar de movimentar-se junto das demais crianças. Ações repetitivas são bastante comuns.

Os Transtornos Globais do Desenvolvimento também causam variações na atenção, na concentração e, eventualmente, na coordenação motora. Mudanças de humor sem causa aparente e acessos de agressividade são comuns em alguns casos. As crianças apresentam seus interesses de maneira diferenciada e podem fixar sua atenção em uma só atividade, como observar determinados objetos, por exemplo.

Com relação à comunicação verbal, essas crianças podem repetir as falas dos outros- fenômeno conhecido como ecolalia - ou, ainda, comunicar-se por meio de gestos ou com uma entonação mecânica, fazendo uso de jargões.

\section{COMO LIDAR COM O TGD NA ESCOLA?}

Crianças com transtornos de desenvolvimento apresentam diferenças e merecem atenção com relação às áreas de interação social, comunicação e comportamento. Na escola, mesmo com tempos diferentes de aprendizagem, 


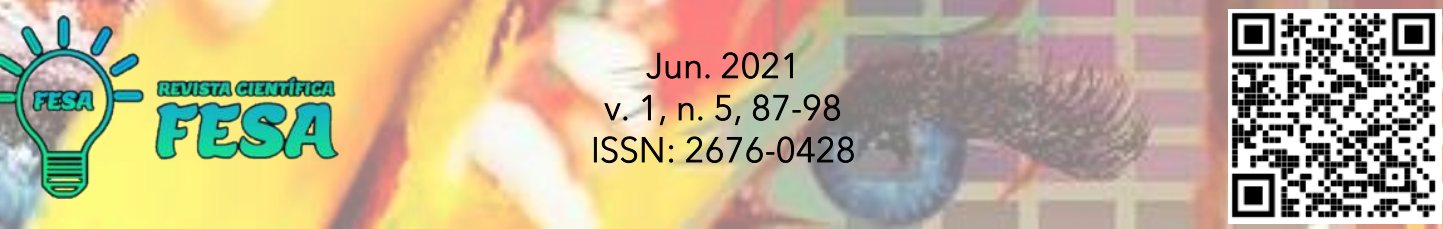

esses alunos devem ser incluídos em classes com os pares da mesma faixa etária.

Estabelecer rotinas em grupo e ajudar o aluno a incorporar regras de convívio social são atitudes de extrema importância para garantir o desenvolvimento na escola. Parte dessas crianças precisa de ajuda na aprendizagem da autorregulação. Ao professor, é fundamental identificar o potencial dos alunos com autismo, sobretudo, fazer ajustes nas atividades sempre que necessário, uma vez que nas escolas municipais de São Bernardo do Campo ele pode contar com a ajuda do profissional responsável pelo Atendimento Educacional Especializado (AEE). Os alunos com TGD costumam procurar pessoas que sirvam como "porto seguro" e encontrar essas pessoas na escola é fundamental para o desenvolvimento.

\section{DISTÚRBIOS DE APRENDIZAGEM E NEUROLÓGICOS NA INFÂNCIA E IN- TEGRAÇÃO SENSORIAL}

A teoria da integração sensorial descrita e desenvolvida por Jean Ayres, no fim dos anos 50 e início dos anos 60, baseada em uma revisão da literatura sobre: desenvolvimento, neurobiologia, psicologia, educação e experiência clínica. Ayres formulou hipóteses nas quais as funções psiconeurológicas podem estar implicadas em distúrbios de aprendizagem.

A definição de integração sensorial, por Ayres (1972), é o processo neurológico que organiza as sensações do próprio corpo e do ambiente de forma a ser possível o uso eficiente do corpo no ambiente.

Ayres sugere que a criança com déficits motores e problemas de integração sensorial de fundo pode ser tratada, influenciando a integração neurofisiológica através do controle do comportamento sensório motor.

Como a teoria da integração sensorial sugere que o objetivo da terapia é melhorar a capacidade da criança de desenvolver e aprender através de um processamento neural eficiente, mudanças não são esperadas antes de 6 meses de intervenção.

Os objetivos específicos dos procedimentos da integração sensorial variarão de acordo com o tipo de disfunção diagnosticada e as diferenças individuais 
$10 \quad$ Jun. 2021

v. 1, n. $5,87-98$

ISSN: $2676-0428$

que fazem cada criança única. Em síntese, os objetivos são individualizados para cada paciente.

A partir do princípio da integração sensorial, podemos destacar a importância e a relevância das práticas esportivas para as crianças com autismo, pois tais práticas agem como um complemento terapêutico prazeroso que leva a criança ao pleno desenvolvimento de sua capacidade motora e seu equilíbrio melhora o processo de socialização, colabora na organização cerebral ajudando a criança a criar uma sequência lógica gradativa que ordena suas ações.

\section{DADOS COLETADOS}

Os quadros a seguir trazem os dados coletados na entrevista com uma professora da rede pública municipal de São Bernardo do Campo que atua junto a uma criança de nome O. A., autista, matriculada no 4ํㅡㄹ Ano do Ensino Fundamental I.

Quadro 1. Dados da entrevista - Perfil

\begin{tabular}{|l|l|}
\hline Pergunta 1 & $\begin{array}{l}\text { Entrevistador: Qual é a sua formação profissional? } \\
\text { Entrevistado: Sou graduada em Educação Física (bachare- } \\
\text { lado e licenciatura) pela FEFISA e pós-graduada em Treina- } \\
\text { mento Desportivo pela FMU. }\end{array}$ \\
\hline Pergunta 2 & $\begin{array}{l}\text { Entrevistador: Há quanto tempo atua nessa área? } \\
\text { Entrevistado: Atuo como profissional da área desde que termi- } \\
\text { nei a faculdade em 2010, mas como professora de Educação } \\
\text { Física Escolar estou há quase } 3 \text { anos, quando entrei na rede } \\
\text { municipal de São Bernardo do Campo em janeiro de } 2014 .\end{array}$ \\
\hline
\end{tabular}

Fonte: Compilado para este estudo.

Após as perguntas mais pessoais, passou-se para a ciência de sua prática enquanto docente de educação física.

Quadro 2. Dados da entrevista - Docência

\begin{tabular}{|l|l|l}
\hline Pergunta 3 & Entrevistador: O que significa inclusão nas aulas de Educação
\end{tabular} Física?

Entrevistado: Participação ativa de todos em busca do desenvolvimento de cada um dentro de suas capacidades, propiciando a socialização e promovendo o respeito às diferenças. 
\begin{tabular}{|l|l|}
\hline Pergunta 4 & Entrevistador: Conhecendo sua turma, sabendo que nela há \\
& um aluno autista, como você prepara suas aulas? \\
& Entrevistado: As aulas de Educação Física são planejadas \\
& com base no Plano de Curso da Escola, onde objetivos e con- \\
& teúdos são previstos para cada ano/ciclo. A partir daí, verifica- \\
& se a necessidade dos alunos que compõe aquela turma e obje- \\
& tivos específicos são propostos de forma a corroborar para o \\
& desenvolvimento global daquela criança.
\end{tabular}

Fonte: Compilado para este estudo.

Dadas as informações anteriores, focalizou-se s perguntas na questão inclusiva, a fim de se compreender como se efetivou a inclusão desse aluno.

Quadro 3. Dados da entrevista - Inclusão

Pergunta 5 Entrevistador: Descreva brevemente uma aula prática cujo $\mathrm{O}$. A. participou.

Entrevistado: Uma das aulas que mais me chamou a atenção, apesar da simplicidade da atividade proposta, foi a de realização de estafetas para o desenvolvimento de habilidades motoras de locomoção e manipulação. A turma se dividiu em três grupos e precisou trabalhar em equipe para pontuar. A princípio, O. A. observou seus colegas e reproduziu o que estavam fazendo, sem que fosse necessária a minha explicação. Conforme o grau de dificuldade das atividades aumentava, O. A. recebia orientação e apoio dos colegas, que em nenhum momento pensaram na pontuação como recompensa. Certamente, a participação efetiva de $\mathrm{O}$. A. em tempo integral foi a maior recompensa para todos nós.

Pergunta 6 Entrevistador: O que a motivou a organizar as Paraolimpíadas na escola? O que os alunos e professores acharam dessa ideia?

Entrevistado: Em 2016 tivemos o Brasil como país sede das Olimpíadas, o maior evento esportivo do mundo onde atletas buscam a superação através de atitudes, índices e medalhas. Então, fizemos um projeto envolvendo toda a escola com o objetivo de ampliar as vivências esportivas dos alunos e fomentar valores olímpicos como amizade, respeito e excelência. A organização das Paraolimpíadas aconteceu por acreditarmos na potencialidade de nossos alunos e na importância da participação de todos, já que a nossa Escola possui diversas crianças com necessidades especiais. As professoras adoraram o projeto e 


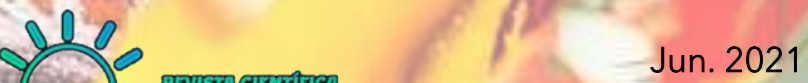

as crianças vibraram muito com a participação dos colegas nas provas das paraolimpíadas.

Fonte: Compilado para este estudo.

Podemos perceber através da entrevista o quanto as relações afetivas são ampliadas durante as aulas de Educação Física na escola, bem como há interesse da professora em desenvolver as habilidades de seu aluno de inclusão.

Quadro 4. Dados da entrevista - Avanços

\begin{tabular}{|l|l|}
\hline Pergunta 7 & $\begin{array}{l}\text { Entrevistador: Quais são os avanços apresentados pelo O. A. } \\
\text { ao longo de 2016? } \\
\text { Entrevistado: O. A. está mais aberto para as possibilidades de } \\
\text { interação e comunicação com os seus colegas. Até mesmo co- } \\
\text { migo, quando proponho uma atividade que não Ihe agrada, ele } \\
\text { consegue se expressar, o que facilita no direcionamento de ati- } \\
\text { vidades que sejam do seu interesse para que tenhamos su- } \\
\text { cesso nos objetivos propostos. }\end{array}$ \\
\hline Pergunta 8 & $\begin{array}{l}\text { Entrevistador: Quais são suas expectativas para 2017 em re- } \\
\text { lação ao O. A.? } \\
\text { Entrevistado: Para 2017, a expectativa em relação ao O. A. é } \\
\text { que ele continue superando suas dificuldades, descobrindo ati- } \\
\text { vidades que goste de realizar, estabelecendo parcerias com os } \\
\text { novos colegas de turma e fortalecendo a nossa relação em } \\
\text { busca da independência dele. }\end{array}$ \\
\hline
\end{tabular}

Fonte: Compilado para este estudo.

Houve ganhos tanto no aspecto social, quanto físico, pois percebe-se que ele foi adquirindo mais interesse e autonomia na realização das tarefas cotidianas. Segundo relatos da mãe:

Esta escola e os professores estão fazendo um trabalho tão rico e dinâmico com meu filho! Lá existe uma equipe empenhada em trabalhar seus potenciais e ele se sente igual aos colegas, isso para mim, é a verdadeira Inclusão. O. A. está se alimentando melhor e fica mais tempo concentrado em casa. Antes ele não prestava muita atenção em filmes e desenhos, realizava todas as lições da escola com ajuda. Agora, ele consegue calcular expressões numéricas de Matemática com material dourado sozinho e faz relatos de situações ocorridas na escola por meio de frases mais elaboradas. Quando participou do Atletismo nas Paraolimpíadas na escola, ganhou dois certificados de $1^{\circ}$ lugar, chegou em casa todo feliz expressando-se de forma clara. Tudo isso para uma mãe, não tem preço (RESPONSÁVEL 1). 
Nas aulas de Educação Física, fica nítido o quanto as crianças se realizam, sejam elas autistas ou não, por isso, acreditamos que a prática de esportes dentro e fora da escola colabora em seu desenvolvimento integral.

\section{CONSIDERAÇÕES FINAIS}

A escola é um espaço vivo e pulsante que tem a responsabilidade pela formação do cidadão, pelo respeito às diferenças, sobretudo, um espaço onde os desafios devem ser vistos de maneira edificante a todos que compõem esse ambiente.

Cabe aos educadores muita reflexão e mudanças de posturas para atenderem às reais necessidades dos seus alunos, afinal, hoje temos a Lei Brasileira de Inclusão e esta é uma realidade. Ainda, há muita resistência por parte de alguns profissionais da Educação. Ouve-se muito nas reuniões pedagógicas burburinhos de que esses alunos deveriam estar numa escola especial ou que os professores não estão preparados para atendê-los.

Acreditamos que falta um olhar mais sensível em relação à inclusão por parte de alguns profissionais, pois as crianças com deficiência estão adentrando as escolas, por isso precisam ser acolhidas e assistidas por todos.

A partir dessa pesquisa, concluímos que o autismo caracteriza-se pela dificuldade de relacionamento entre o autista e outras pessoas, pela demonstração de atrasos no seu desenvolvimento no que se refere à linguagem e à necessidade de manter o ambiente sem mudança, e que para estas crianças é de importante o trabalho psicomotor.

Atualmente, o número de crianças com TGDs, inclusive TEA vem aumentando nas escolas, apesar de existirem cursos de formação que dão subsídios para os professores desenvolverem atividades diversificadas, isso não é suficiente. Acredito que não é o diagnóstico ou laudo do aluno o mais importante, isso pode levar o professor ao conhecimento das principais características de um determinado TGD, mas o que vai nortear o trabalho do professor é a boa vontade e o interesse em propor e superar os desafios que ambos terão pela frente, sobretudo, explorando as potencialidades desses alunos. 
Faz-se necessário desenvolver uma formação continuada para os professores que atuam com esses alunos e que esta formação seja capaz de articular teoria e prática, construindo novos conhecimentos. Quando o educador aprender a ver o mundo através dos olhos de um aluno autista, ele atenderá as suas necessidades. Acreditamos que a afetividade e a persistência sejam a chave para uma nova forma de ensinar e, também, de aprender.

\section{REFERÊNCIAS BIBLIOGRÁFICAS}

AYRES, J. Sensory integration and learning disorders. Los Angeles: Western Psychological Services, 1972.

FILHO, José Ferreira Belisário Filho, CUNHA, Patrícia. A Educação Especial na Perspectiva da Inclusão Escolar. Ministério da Educação - Secretaria de Educação Especial - Universidade Federal do Ceará. Coleção: Brasília, 2010.

KANNER, L. Affective disturbances of affective contact. Nervous Child, 2, 217-250, 1943.

\section{SITES CONSULTADOS}

ABRAÇA. Lei Brasileira de Inclusão. Disponível em: http://abraca.autismobrasil.org/lei-brasileira-de-inclusao-lbi-em-perguntas-e-respostas/ Acesso em 25 jun. 2021.

AUTISMO. Ginástica Olímpica. Disponível em: http://autismoerealidade.org/noticias/ginastica-olimpica-ajuda-criancas-autistas-a-superar-obstaculos/ Acesso em 25 jun. 2021.

INSTITUTO NEURO SABER. O que é Autismo ou Transtorno do Espectro Autista (TEA)? Disponível em: http://entendendoautismo.com.br/artigo/o-que-eautismo-ou-transtorno-do-espectro-autista-tea/ Acesso em 25 jun. 2021.

NOVA ESCOLA. O que são os Transtornos Globais do Desenvolvimento (TGD)? Disponível em: https://novaescola.org.br/conteudo/51/o-que-sao-ostranstornos-globais-do-desenvolvimento-tgd Acesso em 25 jun. 2021. 